\title{
Spinal cord injury: prognosis for ambulation based on quadriceps recovery
}

\author{
K S Crozier MD, Ling Ling Cheng BS, V Graziani MD, G Zorn MD, G Herbison MD, \\ J F Ditunno Jr MD
}

Department of Rehabilitation Medicine, Thomas Jefferson University Hospital, $11^{\text {th }}$ and Walnut Streets, Suite 9604 Gibbon, Philadelphia, PA 19107, USA.

The purpose of this study was to determine if early recovery of quadricep muscle strength post spinal cord injury (SCI) is a useful predictor of future ambulation. Seventeen C4-T10 motor incomplete (Frankel C) spinal cord injured patients adimitted to our center between March 1988 and April 1990 were examined within 72 hours to one week post injury. All patients had initial quadricep strengths $\leqslant 2 / 5$ in both legs. Strength in the strongest quadricep was followed prospectively at intervals from admission to one year post injury. Recovery time to a $>3 / 5$ quadricep was established for each patient. Patients were categorized into 2 groups: FA $(n=11)$ were those patients who achieved functional ambulation and NA $(n=6)$ were those subjects who were nonambulators. Functional ambulators were defined as those patients who were able to walk in the household and/or the community while non ambulators were those who either did not ambulate or did so only for exercise. All patients $(n=9)$ who achieved a $>3 / 5$ quadricep by 2 months post SCI became functional ambulators whereas in the group of 8 patients who did not achieve a $>3 / 5$ by 2 months, only 2 became functional ambulators. This result was found to be significant using a point-by-serial correlation with $p<0.05$. In conclusion, motor incomplete spinal cord injured patients who recovered to a $>3 / 5$ quadricep strength by 2 months post injury had an excellent prognosis for subsequent ambulation by 6 months post injury.

Keywords: spinal cord injury; ambulation; prognosis; quadriceps muscles.

\section{Introduction}

Several investigators have studied functional recovery in spinal cord injured SCI patients, ${ }^{1-5}$ with a subset who have focused on recovery to walking. ${ }^{2-4,6}$ The National SCI Center Data Base $^{7}$ for spinal cord injury noted that motor useless incomplete spinal cord patients (Frankel C, Table I) made up $8.5 \%$ of the total SCI population in 1985. It was reported that $46 \%$ of these patients remained Frankel $\mathrm{C}$ at discharge, the remaining $64 \%$ had a change in their Frankel grade, the majority progressing to motor useful status (Frankel D).

Frankel et al observed that 16 of 21 motor incomplete (Frankel C) patients recovered

Table I Frankel classification of neurological deficit after spinal cord injury

\begin{tabular}{|c|c|}
\hline Frankel A & Complete: no motor or sensory function below level of lesion \\
\hline Frankel B & $\begin{array}{l}\text { Sensory only preserved: complete motor paralysis below level of lesion with } \\
\text { some preservation of sensory function }\end{array}$ \\
\hline Frankel C & $\begin{array}{l}\text { Motor useless: some motor power present below level of lesion, but it is of no } \\
\text { practical use }\end{array}$ \\
\hline Frankel D & $\begin{array}{l}\text { Motor useful: useful motor power below level of lesion; these patients can move } \\
\text { lower limbs and many can walk, with or without aids }\end{array}$ \\
\hline Frankel E & $\begin{array}{l}\text { Recovery: free of neurological symptoms, no weakness, sensory loss, or } \\
\text { sphincter disturbance; abnormal reflexes may be present }\end{array}$ \\
\hline
\end{tabular}


to either motor useful or normal function by discharge. ${ }^{1}$ Similarly, Folman and Marsi found that $86 \%$ of motor incomplete patients with as little as a 'muscle flicker' in the lower extremities recovered to motor useful function and $60 \%$ recovered completely. ${ }^{5}$ This was a retrospective study with patients followed for one to 21 years post injury. The ambulatory status was not defined in either study. ${ }^{5}$

Maynard et al suggested that the Frankel classification of neurological deficits be modified by introducing a new functional category titled 'walking', defined as motor power in the legs adequate for a patient to be a 'community walker.'2 This definition allowed for the use of an ankle foot orthosis and upper extremity aids but not a knee ankle foot orthosis. They observed that while 27 of $31(87 \%)$ motor incomplete subjects were walking at one year post SCI, only 8 patients were fully recovered. In this analysis Frankel $\mathrm{C}$ and $\mathrm{D}$ patients were grouped together as 'motor incomplete'. Maynard and his associates also stressed the improved accuracy of prognosticating future outcome based on the 72 hour examination rather than immediately post injury. ${ }^{2}$ It should be noted however that the authors did not define 'adequate motor power' either at admission or at follow up. They reported that 'cognitively intact' patients who are motor incomplete (ie Frankel C and D) at 72 hours and do not have 'other problems' have an excellent prognosis for functional walking estimated at $90 \%$ by the authors. $^{2}$

Daverat $e t a l^{4}$ used an initial Yale Scale Score $^{8}$ to predict recovery to 'walking status' which they defined as adequate motor power in the legs allowing patients to be functional walkers with or without an orthosis. The Yale scale attempts to quantify motor and sensory function on a scale of one to ten, however it does not account for sacral sparing. The authors defined ambulation as almost 'normal' or 'household' distances. They found that $28 \%$ of 157 consecutively admitted SCI patients, of all functional grades, became functional walkers. This paper concludes that a positive predictor for ambulation was a Yale scale score of greater than $6 .{ }^{4}$ This study grouped all functional grades together for analysis. Although patients were all studied at admission, it did not define how long this was post injury. The conditions for ambulation and the degree of motor power were not described.

Hussey and Stauffer, in a retrospective study, defined 4 categories of ambulatory function: community, household, exercise, and non ambulatory. ${ }^{3}$ They concluded that quadricep function was an important determination in the level of ambulation achieved. They found that $94 \%$ of the community and $92 \%$ of the household ambulatory subjects had fair or better quadricep function in one leg. In contrast, $76 \%$ of those individuals at the exercise level and $90 \%$ of those subjects who were non ambulatory had no quadricep function. ${ }^{3}$ It is important to note that this study evaluated patients who were already ambulatory and looked retrospectively at the requirements. They did not predict functional outcome based on the initial strength.

The above studies were retrospective $e^{1,2,5}$ and not designed to predict future ambulation potential from the admission examination. The present study was designed to prospectively follow Frankel $\mathrm{C}$ motor incomplete SCI patients to investigate when they recovered functional strength in their quadriceps predictive of future ambulation.

\section{Methodology}

Twenty-four Frankel C patients with neurological levels from C4 to T10 were admitted to our center between March 1988 and April 1990. For the purpose of the present study every patient who fulfilled the following criteria was considered appropriate for analysis. Only patients admitted within 72 hours and followed for one year post SCI with the ability to cooperate with a neurological analysis and an initial quadricep muscle strength from $0 / 5$ to $2 / 5$ were included in this study. Patients were excluded from the study if they had pelvic and/or bilateral leg fractures because these problems would have interfered with muscle testing of the lower extremities. Based on these rigid selection criteria 17 patients were studied.

All patients were followed prospectively 
using standardized forms for motor, ${ }^{9,10}$ and sensory neurological examinations which met criteria set by the American Spinal Injury Association (ASIA). ${ }^{10}$ Data were recorded on admission, 72 hours, one week, weekly for 3 weeks, monthly for 3 months and at 6 and 12 months post injury. Eleven patients were followed for one year and the remaining 6 were followed for 6 months. Manual muscle tests (MMT) performed according to modified methods described by Brunnstrom and Dennen ${ }^{9}$ were carried out by either a staff physiatrist or trained technicians. Specifically, quadricep strength was tested with the patient in the supine position with the examiner's forearm beneath the knee such that both knee and hip were in $30^{\circ}$ of flexion. Patients were then assigned quadricep motor grades according to their ability to extend the leg and graded by the standards of ASIA. ${ }^{10}$ For those patients with less than $3 / 5$ strength and who were unable to side lie, the hip was externally rotated $50^{\circ}$ and the patient attempted to extend the knee with the leg support by the examiner. Motor grades for both quadriceps were recorded at the specified time intervals (see above). Recovery time to a $>3 / 5$ quadricep was established by reviewing the MMT results for each patient.

The sensory examination was done by examining key sensory areas for pin and touch. ${ }^{10}$ All patients had some pin sensation, either normal or decreased, below the zone of partial preservation.

Ambulation was categorized into 4 groups (Table II): community, household, exercise, and no ambulation. ${ }^{3}$ Whereas motor power and sensation were evaluated prospectively, ambulation levels at 3 months to one year post injury were established retrospectively by reviewing weekly physical therapy summaries, outpatient physician evaluations and by contacting patients after discharge by phone. Patients achieving either community or household ambulation were considered functional ambulators (FA) while those with exercise or no ambulation were considered non ambulators (NA). The percentage of subjects that achieved $>3 / 5$ strength in their strongest quadriceps by $1,2,3$, and 6 months post injury was determined. The percentage of patients that achieved functional ambulation by 6 months was determined in relation to initial quadriceps strength. The relationship between time to recovery of the strongest quadricep to $>3 / 5$ and the likelihood of functional ambulation was analyzed. In addition age and level of injury were analyzed for their relationship to ambulation. All results were analyzed by the point-by-serial correlation and a value of $p<0.05$ was considered significant.

\section{Results}

Seventeen patients met the selection criteria; there were 14 men and 3 women ranging from 17 to 59 years of age. The injuries were caused by falls in 6 cases, motor vehicle accidents in 6 , gunshot wounds in 2, sports related injuries in 2 , and stabbing in one. There were 13 quadriplegics (C4 to $\mathrm{C} 6$ ) and 4 paraplegics (T4 to T10). All patients were followed for one year post injury.

Initial quadricep strength ( 72 hours to one week) was only predictive of future ambulation in patients with an initial grade $2 / 5$ quadricep muscle strength. This group all

Table II Ambulation levels ${ }^{3}$

\begin{tabular}{ll}
\hline Community & $\begin{array}{l}\text { ambulates for reasonable distances both in and out of the home unassisted by } \\
\text { another person, may use crutches or wheelchair for exceptionally long } \\
\text { distances } \\
\text { ambulation in home with relative independence but unable to ambulate } \\
\text { outside of the home for any significant distances and uses wheelchair outside }\end{array}$ \\
Household & $\begin{array}{l}\text { ambulation under controlled conditions and with significant assistance } \\
\text { functional mobility attained entirely with wheelchair }\end{array}$ \\
\hline Exercise &
\end{tabular}

Community and household levels were considered functional ambulation.

Exercise and no ambulation were considered non ambulation. 
achieved a greater than grade 3 quadricep by 2 months and became functional ambulators. Although initial quadricep scores of $0 / 5$ and $1 / 5$ were not predictive of future ambulatory status, some of these patients became ambulatory and some did not. Therefore whereas an initial quadricep strength of $2 / 5$ predicted ambulation, an initial quadricep strength of $0 / 5$ or $1 / 5 \mathrm{did}$ not necessarily indicate a poor prognosis for functional ambulation (Tables III and IV).

Patients with greater initial quadricep scores were most likely to achieve a $>3 / 5$ score by 2 months post SCI. Twenty-five percent, $44 \%$ and $100 \%$ of those patients with initial quadricep scores of $0 / 5,1 / 5,2 / 5$, respectively, achieved a $>3 / 5$ quadricep muscle strength by 2 months post injury
(Fig 1). At 3 months post SCI $75 \%, 83 \%$, and $100 \%$ of those patients with initial quadricep scores of $0 / 5,1 / 5$ and $2 / 5$ respectively, achieved a $>3 / 5$ quadricep strength (Fig 1). At 6 months post SCI $16 / 17$ patients had achieved a $>3 / 5$ quadricep muscle strength. However we noted that of those patients who became functional ambulators $(n=11)$, most $(n=9)$ had gained $>3 / 5$ quadricep strength at or before 2 months post injury (Table IV).

There were 6 patients who were non ambulators (NA), 4 with no ambulation and 2 who were exercise ambulators (Table IV, patients $3 \& 6$ ). All patients, except one, achieved a $>3 / 5$ quadricep strength by one year (Table IV, patient 2). The N/A patients ranged in age from 24 to 59 years (mean

Table III Functional ambulators $(\mathrm{n}=11)$

\begin{tabular}{|c|c|c|c|c|c|c|}
\hline \multirow{2}{*}{$\frac{\text { Patient }}{1}$} & \multirow{2}{*}{$\frac{\text { Age }}{29}$} & \multirow{2}{*}{$\frac{\text { Level of injury }}{\mathrm{C} 4}$} & \multirow{2}{*}{$\frac{\text { MMT }}{0}$} & \multirow{2}{*}{$\frac{\text { Time }>3 / 5}{6 \mathrm{mo}}$} & \multicolumn{2}{|c|}{ Ambulation L \& T } \\
\hline & & & & & $E-6$ & $C-12$ \\
\hline 2 & 18 & C5 & 0 & $1 \mathrm{mo}$ & H -3 & $C-6$ \\
\hline 3 & 28 & T10 & 0 & $3 \mathrm{mo}$ & H -6 & \\
\hline 4 & 27 & $\mathrm{~T} 4$ & 1 & $1 \mathrm{mo}$ & $\mathrm{H}-3$ & $C-6$ \\
\hline 5 & 17 & $\mathrm{C} 4$ & 1 & $2 \mathrm{mo}$ & $\mathrm{H}-3$ & C -6 \\
\hline 6 & 34 & $\mathrm{C} 4$ & 1 & $1 \mathrm{mo}$ & $C-3$ & $C-6$ \\
\hline 7 & 17 & T5 & 1 & $1 \mathrm{mo}$ & $\mathrm{H}-3$ & $C-6$ \\
\hline 8 & 33 & $\mathrm{C} 4$ & 2 & $2 \mathrm{mo}$ & $\mathrm{H}-3$ & $C-6$ \\
\hline 9 & 56 & $\mathrm{~T} 8$ & 2 & $1 \mathrm{mo}$ & $\mathrm{H}-3$ & H -6 \\
\hline 10 & 50 & C6 & 2 & $1 \mathrm{mo}$ & C -3 & \\
\hline 11 & 51 & C5 & 2 & $1 \mathrm{mo}$ & $E-3$ & H -6 \\
\hline
\end{tabular}

$\mathrm{MMT}=$ the initial motor strength of the quadricep strength in the weakest extremity at 72 hours to one week post SCI.

Time $>3 / 5=$ the month when the quadricep motor strength achieved a MMT of $>3 / 5$.

Ambulation $\mathrm{L} \& \mathrm{~T}$ : $\mathrm{L}=$ level of ambulation, $\mathrm{T}=$ time in months to achieve this level of ambulation. See Table II for explanation.

Table IV Non ambulators $(\mathrm{n}=6)$

\begin{tabular}{lllccl}
\hline Patient & Age & Level of injury & MMT & Time $>3 / 5$ & Ambulation L \& T \\
\hline 1 & 28 & C4 & 0 & 3 mo & N \\
2 & 59 & C4 & 1 & N & N \\
3 & 51 & C5 & 1 & 3 mo & N \\
4 & 47 & C4 & 1 & 3 mo & N \\
5 & 58 & C5 & 1 & 3 mo & E \\
6 & 24 & C5 & 1 & 6 mo & \\
\hline
\end{tabular}

See footnote to Table III.

*refers to the patient who did not achieve a $>3 / 5$ quadricep during the study period. 


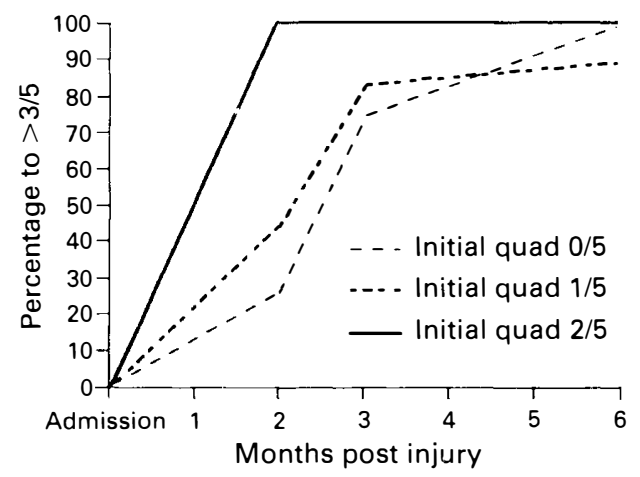

Figure 1 Gain in quadriceps MMT to $>3 / 5$ in SCI patients, grouped by their initial quadriceps strength and followed for 6 months post injury.

44 years), and all were quadriplegic with C4-C5 neurological levels.

Eleven subjects became functional ambulators, 8 at the community and 3 at the household levels. Eight out of the 11 patients who were FA were ambulatory by 3 months (Table III, patients 2 and 4-11) while 2 became ambulatory by 6 months (Table III, patients 3 and 11) and one by 12 months (Table III, patient 1 ). These patients ranged from 17 to 58 years of age (mean 32.6 years). These subjects included 7 quadriplegics ( $\mathrm{C} 4$ to $\mathrm{C} 10)$ and 4 paraplegics (T4 to T10).

Nine patients who were FA $(\mathrm{n}=11)$ achieved a $>3 / 5$ quadricep strength by 2 months whereas only 2 FA subjects achieved $\mathrm{a}>3 / 5$ quadricep strength after 2 months (Table III, patients $1 \& 3$ ). No NA $(n=6)$ patients achieved a $>3 / 5$ strength by 2 months post SCI; however 4 achieved $>3 / 5$ by 3 months and one by 6 months post SCI (Table IV).

There was no statistical difference between patients who were FA \& NA when analyzed for age or level of injury (Table $\mathrm{V})$. There was a significantly greater number of subjects who recovered quadriceps strength to $>3 / 5$ by 2 months post injury who achieved functional ambulation compared to the non ambulators $(p<0.05)$ (Table VI).

\section{Discussion}

This study demonstrated that Frankel C SCI patients who achieved a $>3 / 5$ quadricep strength by 2 months post injury had an excellent chance of becoming functional ambulators. Eleven of 17 (11/17) Frankel C subjects $(64 \%)$ became functional ambulators. This result concurs with The National Data Base. ${ }^{7}$ These results at first appear to contradict Maynard et al's work who found that $87 \%$ of motor incomplete patients ambulated. ${ }^{2}$ However Maynard and associates grouped together both Frankel $\mathrm{C}$ and $\mathrm{D}$ patients for analysis whereas this study did not include any patients who were initially Frankel D. The unique finding in the present study was the strong relationship between time of recovery to $>3 / 5$ quadriceps strength, and the likelihood of future functional ambulation. As our patient population was small it was not possible to

Table V

\begin{tabular}{lccc}
\hline & Quads & Paras & $\begin{array}{c}\text { Age (yrs) } \\
\text { mean }\end{array}$ \\
\hline Group FA & 7 & 4 & 32.6 \\
Group NA & 6 & 0 & 44 \\
\hline
\end{tabular}

Quads = quadriplegic patients with levels of injury from $\mathrm{C} 4$ to $\mathrm{C} 8$.

Paras = paraplegic patients with levels of injury from T4 to T10.

Table VI Time to quadricep muscle strength at $>3 / 5$

\begin{tabular}{lcccc}
\hline Achieved & Total & $<2$ months & $>2$ months & Never \\
\hline Functional Ambulator & 11 & 9 & 2 & 0 \\
Non ambulator & 6 & 0 & 5 & 1
\end{tabular}

There was a statistically significant greater number of patients $(p<0.05)$ who became functional ambulators when quadricep strength was $>3 / 5$ at 2 months or less. 
ascertain a relationship between age, level of injury and pin sensation.

A previous study has suggested a strong correlation of future ambulatory status with age in central spinal cord injured patients, noting that over age 50 the prognosis to become ambulatory was significantly worse than for patients less than 50 years old. ${ }^{11}$ Our patient population was small and rather homogeneous in age which may account for the lack of relationship between age and ambulatory status. Also, we found no relationship between the initial level injury and recovery of ambulation. This finding is consistent with Deverat et al. ${ }^{4}$ Previous studies by Crozier et al noted a statistically significant improvement in prognosis for ambulation in Frankel B patients who had sparing of pin sensation below the zone of injury within 72 hours post SCI. ${ }^{12}$ However in the present study no subjects (FA or NA) had the complete absence of pin sensation and therefore this factor could not be analyzed in relation to ambulation.

Obviously the mere presence of a $>3 / 5$ quadricep strength did not equate ambulation potential as all but one patient eventually achieved $>3 / 5$ quadricep strength.
We did not collect data to analyze the effects of spasticity and position sense on ambulation and perhaps these are factors which impacted on the inability to ambulate in some patients in this study. Despite the fact that these were not addressed in this study, our results remain significant. These factors will be analyzed in a future study. In summary this study showed that quadriceps MMT at $<1$ week post SCI does not predict future functional ambulation, except in patients with initial 2/5 quadricep MMT. In addition, patients with quadricep strength that is $>3 / 5$ by 2 months post SCI had an excellent prognosis for functional ambulation.

\section{Acknowledgements}

The authors wish to thank Michelle Cohen PhD and Gregory Purnsley for their help with the statistical analysis.

This study was supported in part by awards from the National Institute on Disability and Rehabilitation Research to the Regional Spinal Cord Injury Center of Delaware Valley (\#G008535135) and the National Rehabilitation Research and Training Center in Spinal Cord Injury (\#H133B80017).

\section{References}

1 Frankel HL, Hancock DO, Hyslop G, Melzak J, Michaelis LS, Ungar GH et al (1969-1970) Value of postural reduction in initial management of closed injuries of the spine with paraplegia and tetraplegia. Part I. Paraplegia 7: 79-192.

2 Maynard FM, Reynolds GG, Fountain S, Wilmont C, Fanilton R (1979) Neurological prognosis after traumatic quadriplegia. Three year experience of California Regional Spinal Cord Injury System. $J$ Neurosurg 50: 611-16.

3 Hussey TW, Stauffer SE (1973) Spinal cord injury: Requirements for ambulation. Arch Phys Med Rehabil 54: $544-47$.

4 Daverat P, Sibrac MC, Dartigues JF, Mazaux JM, Marit E, Debelleix N et al (1988) Early prognostic factors for walking in spinal cord injuries. Paraplegia 26: 255-261.

5 Folman Y, Masri WE (1989) Spinal cord injury: prognostic indicators. Br J Accident Surg 20(2): 92-3.

6 Cherrazzi B, Wagner FC, Collins FW, Free, Am DRL (1981) A scale for evaluation of spinal cord injury. $J$ Neurosurg 54: 310-315.

7 Stover SL, Fine PR (1986) Spinal Cord Injury: The Facts and Figures. University of Birmingham Alabama.

8 Lazar RB, Yarkony GM, Ortolare D, Heineman AW, Perlaw E, Lovell L et al (1989) Prediction of functional outcome by motor capability after spinal cord injury. Arch Phys Med Rehabil 79: 819-22.

9 Brunnstrom F, Dennen M (1931) Round table on muscle testing. Annual Conference on American Physical Therapy Association, Federation of Crippled and Disabled, Inc, New York: 1-12.

10 American Spinal Injury Association (1982) Standards for neurological classification of spinal injury patients. Chicago.

11 Penrod LE, Hedge SK, Ditunno JF (1990) Age affect in prognosis for functional recovery in acute, traumatic central cord syndrome. Arch Phys Med Rehabil 71: 963-69.

12 Crozier KS, Grazaini V, Ditunno JF, Herbison GJ (1991) Spinal cord injury: prognosis for ambulation based on sensory examination in patients who are initially motor complete. Arch Phys Med Rehabil 72: 119-121. 